\title{
Implications of alcohol consumption of fishers in three major reservoirs of Sri Lanka on
}

\section{some aspects of reservoir fisheries management}

\author{
Wickremasinghe, E.S. ${ }^{1^{*}}$, Dematawewa, C.M.B. ${ }^{2}$ and Edirisinghe, U. ${ }^{2}$ \\ ${ }^{1}$ National Aquaculture Development Authority of Sri Lanka \\ ${ }^{2}$ Department of Animal Science, University of Peradeniya, Peradeniya, Sri Lanka
}

\begin{abstract}
A study was conducted to investigate the impact of alcohol consumption pattern of fishers on their socioeconomic status and involvement in fisheries management activities in Victoria, Sorabora and Ulhitiya reservoirs in Sri Lanka. ANOVA procedure $(\alpha=0.05)$ showed that fishers that consume alcohol rarely (<3 times/month) had significantly higher mean daily income (Rs. 1260.00) compared with daily drinkers (Rs. 841.00). Chi square analysis $(\alpha=0.05)$ showed that the negative association between living standard and alcohol consumption was significant only in Sorabora reservoir. In Sorabora and Ulhitiya, regular alcohol consumption had a significantly negative impact on amount of cash saved by the household. Smoking was significantly associated with alcohol consumption in all three reservoirs. Regular users of alcohol exhibited lower tendency to comply with regulations (e.g. boat registration) in Victoria and Ulhitiya. Holding positions in the fisheries organization, participation at trainings programmes, and attending monthly meetings regularly were significantly associated with alcohol consumption of fishers in Victoria. In Ulhitiya, fishers who voluntarily participated in Government operated raids were less prone to consume alcohol. This study revealed that associations between alcohol consumption of fishers and the socioeconomic and management aspects vary among the reservoirs indicating the need for reservoir specific aquatic resource management strategies.
\end{abstract}

Keywords: Aquatic resource management, Fisheries Organization, Inland reservoirs, Reservoirspecific, Socioeconomic aspects.

\section{Introduction}

The potential for development of aquaculture sector in Sri Lanka is substantial with the availability of about 260,000 ha of freshwater bodies scattered around the island (Anon., 2009). The impact of fisheries sector on the national economy of the country is significant and the present contribution to the total GDP is $2 \%$ (Anon., 2013). The current per capita fish consumption of the population is around 17 $\mathrm{kg}$ per year and ideally it should be increased to $22 \mathrm{~kg}$ per year in order to ensure the acceptable nutrient intake

Corresponding author: shehanwickrema@yahoo.com Received: 14.11.2018
(Anon., 2016a). This requirement could be fulfilled realistically since the freshwater bodies of the country have the potential to produce 125,000 MT of fish annually (Anon., 2016b). However, the freshwater fish production in 2017 was reported to be only 84,540 MT (Anon., 2018). Many of the previous studies conducted in western countries have proven high prevalence of alcohol usage among fishermen but the published information on developing countries is scanty (Chinnakaliet al., 2016; Lawrie et al., 2004). In South India, majority of the fishers were reported to use alcohol during fishing activities and their

https:/ / orcid.org/0000-0003-2876-2405 Accepted: 01.02.2019 
usage is independent of the alcohol using habits of their family members (Chinnakaliet al., 2016). Lawrie et al. (2004) observed that in Scotland fishermen lacked knowledge about the safe levels of alcohol consumption and they should be made aware of the danger of over drinking. Tumwesigyeet al. (2012) showed that alcohol consumption is strongly correlated with sexual behaviors in Uganda and the level of correlation differs by occupation. George et al. (1994) has found that use of alcohol is correlated negatively with education level but positively with number of children per family in coastal communities of South India. Rane et al. (2016) observed a positive association between alcohol consumption and income level in fishing communities in South India but no relationship with respondent's job stress and health status. The studies of socioeconomic aspects and human behavior in fishing communities must pay due attention to the uniqueness of each reservoir (Wetzel, 1983) where nature and severity of the problems could be reservoir dependent. Although Governments implement regulatory measures and various fisheries management activities, the attitudes of the fishing community and their willingness to be involved in reservoir management activities can be detected by their willingness to participate at the meetings and raids, be office bearers, obtain license for boats and nets, and comply with various other regulations, which may have a bearing upon their alcohol related behaviours. Therefore, this study was carried out to quantify and compare the level of alcohol consumption of the fishers in three different major perennial reservoirs (Victoria, SoraboraandUlhitiya) in Sri Lanka; to quantify the level of association of the socioeconomic and management related factors of those fishing communities with alcohol consumption of the fishermen; and to identify the implications of those habits on management of those aquatic resources.

\section{Materials and methods}

\section{Locations of the Study}

This research study was conducted with the participation of fishing communities of three randomly selected perennial reservoirs in Sri Lanka namely Victoria, Sorabora and Ulhitiya.Victoria $(2,380$ ha at FSL) is a major perennial reservoir having a deeper gradient and fed by Mahaweli river and Huluganga. It was primarily constructed for irrigation and hydropower generation. Since it has a characteristically irregular dendritic morphology, fishers had formed ten different fishing landing sites in order to facilitate fishing activities properly. Ulhitiya $(1,261$ ha at FSL), the next major perennial reservoir, is mostly surrounded by wildlife area and fed by Mahaweli south canal and UlhitiyaOya. Fishing community in Ulhitiyareservoir used two fishing landing sites. Sorabora(461 ha at FSL) is a medium scale tank fed by Mahaweli south cannal and Diyabana-oyaand the fishermen were organized under two landing sites. Fisheries management in those reservoirs is governed primarily by the National Aquaculture Development Authority of Sri Lanka (NAQDA) with the support of other responsible Government authorities such as MahaweliAuthority, Irrigation Department, Forestry and Wildlife Department, administrative institutes and law enforcing agencies following a co-management approach (Fernando et al., 2015).

\section{Data Collection and Analysis}

During 2014-2015 period, a comprehensive survey was conducted in those reservoirs with the participation of active fishermen and their families in the fishing communities. As the fishing communities 
are relatively small in most perennial reservoirs in Sri Lanka, all fishermen in the community during the study period were considered for the survey without sampling (132, 125 and 111 fishers in Victoria, Sorabora and Ulhitiya reservoirs, respectively). The information related to alcohol consumption and socioeconomic and management aspects was collected by using a pre-tested structured questionnaire. Alcohol consumption pattern of individual fishermen was measured categorically as none (teetotalers), rarely (once or twice a month), occassionally (3-15 times a month), and regularly (>15 days a month). Socioeconomic factors considered for the analysis were level of education (none, primary, secondary and tertiary), nature of fishing (full-time, part-time), smoking (none, rarely, occassionally, daily), mean daily income across the year (Rs.), savings from income earned $(0 \%, 1-5 \%, 6-10 \%$ and $>10 \%$ of income) and the living standard ranked based on material wealth and basic necessasities of the household (poor, fair, average, satisfactory). Aquatic resources management related factors considered were participation in fisheries Organization activities (active, inactive), positions held in their fisheries organization (currently holding, previously held, and never held), participation at organizational meetings (yes/no), involvement in illegal fishing activities (yes/no), loans obtained from the organization (yes/no), licesing and registration of fishing gear and boats (yes/no), trainings obtained from the organization (yes/no), net and boat subsidies received (yes/no), voluntary participation in raids conducted by the Government officials (yes/no), and responses on their attitudes and opinions such as willingness to comply with fisheries regulations (yes/no), willingness to organize into fisheries societies (yes/no), belief that organizing of communities is useful to improve their living standards (yes/no) etc.). Management practices adopted by the responsible Government Agencies were obtained by interviewing those Government authorities.Information on management activities and issues, and Fisheries Organizations of the three reservoirs were recorded from the monthly meetings of those organizations throughout the study period.

The relevant categorical variables were coded and the relative frequency of each category was calculated. Initially, analysis of variance procedure was carried out to determine the effects of reservoir, level of alcohol consumption and their interaction on mean daily income of fishers. Duncan's New Multiple Range test was used for mean separation. In order to determine the association between alcohol consumption and each of the socioeconomic and management variables, initially Chi-square analysis was performed using PROC FREQ option in $S A S \AA$ software package at $\mathrm{P}=0.05$ (SAS Institute Inc., 2008). Subseguenty, in order to perfome an in-depth analysis on association of alcohol consumption pattern of fishers with other variables studied, linear logistic model analysis was performed considering three associated variables at a time (Greene, 2000). The following logistic model was applied to investigate the odds and relative tendency of consuming alcohol by the other factors:

$$
\begin{aligned}
\ln \left(\frac{P_{i j k}}{1-P_{i j k}}\right) & =\alpha+\beta_{i}+\gamma_{j}+\delta_{k} \\
& +(\beta \gamma)_{i j}+(\beta \delta)_{i k}+(\gamma \delta)_{j k}
\end{aligned}
$$

where, $\alpha=$ intercept; $\beta_{i}, \gamma_{j}$ and $\delta_{k}$ are $\mathrm{i}^{\text {th }}, \mathrm{j}^{\text {th }}$ and $\mathrm{k}^{\text {th }}$ levels of the three associated factors respectively (main factors and their 2-way interactions). $P_{i j k}$ is the proportion of fishers consumed alcohol at the $\mathrm{i}^{\text {th }}, \mathrm{j}^{\text {th }}$ and $\mathrm{k}^{\text {th }}$ levels of the three factors considered respectively 
and $1-P_{i j k}$ is the proportion not consumed alcohol and therefore, $\left(P_{i j k} / 1-P_{i j k}\right)$ is the odds of consuming alcohol. Therefore, $\left(P 1_{i j k}\right.$ $\left./ 1-P 1_{i j k}\right) /\left(P 2_{i j k} / 1-P 2_{i j k}\right)$ means the odds between two levels ( $P 1$ and $P 2)$ of an associated factor considered gives the respective odds ratio, which implies the tendency of alcohol consumption by one level over the other of the factor. In linear logistic model analysis, response variable (alcohol consumption) is treated as binary (Greene, 2000). Thus analysis was initially carried out treating alcohol consumption level as teetotalers and all others. Subsequently analysis was repeated using other possible binary classifications such as teetotalers \& occasional and frequent \& daily; and non-daily vs daily to detect most significant associations. Three factors were considered at a time of analysis since including a large number of factors and their interactions in the model with limited number of fishers create issues with respect to degrees of freedom. Smoking factor (4 levels) was converted into a binary variable as non-smokers versus smokers (including rare, occasional and daily smokers) for linear logistic analysis. In addition, the binary classification was tested in other possible ways as well such as less smoking (none or rare) versus more smoking (occasional or daily) and non-daily (none, rare, occasional) versus daily smokers to find significant relationships of smoking with alcohol consumption in individual reservoirs. The four categories of living standard were also transformed into binary form as unfavourable (poor or fair) versus favourable (average or satisfactory) for linear logistic analysis. Saving habits was converted into binary as poor saving habits ( $<5 \%$ or less of income) versus better saving habits $(6 \%$ or more of income). The variable on willingness to hold positions was also converted to binary form as not willing (never held) versus willing (held previously or presently holding). Maximum likelihood method using CATMOD procedure in SAS software was used to obtain the parameter estimates and confidence intervals for respective odds ratios (SAS Institute Inc., 2008).

\section{Results and Discussion}

\section{Alcohol consumption}

Table 01 shows the alcohol consumption pattern of fishing communities of the three reservoirs studied. Chi square analysis showed that the three reservoirs were different with respect to frequencies of alcohol consumption among fishers $(\mathrm{P}<0.05)$. Victoria and Sorabora reservoirs had fishers with greater consumption of alcohol (about 80\% and 88\%, respectively) compared to Ulhitiya community (about $65 \%$ ). Reservoir management issues could emerge due to frequent alcohol abuse in fishing communities. Alcohol related behavioral changes were shown to be associated with improper fishing practices such as illegal fishing in reservoirs in Sri Lanka (Wickremasinghe et al., 2018). In addition, frequent alcohol consumption aggravates the need for extra earnings from whatever means available. 
Table 01: Percentage of fishers grouped according to their frequency of alcohol consumption in the fishing communities of three reservoirs

\begin{tabular}{lcccc}
\hline \multirow{2}{*}{ Reservoir } & \multicolumn{4}{c}{ Level of alcohol consumption (\%) } \\
\cline { 2 - 5 } & Teetotalers & Rarely taken & Occasionally & Daily \\
\hline Victoria & 19.7 & 16.7 & 52.3 & 11.3 \\
Sorabora & 12.0 & 16.8 & 54.4 & 16.8 \\
Ulhitiya & 35.1 & 14.4 & 33.3 & 17.2 \\
\hline
\end{tabular}

\section{Smoking}

In this study, it was found that the three reservoirs were not significantly different with respect to frequencies of smoking among fishers $(\mathrm{P}>0.05)$. However, Chi square analysis proved that association between alcohol consumption and smoking of the fishers was significant $(\mathrm{P}<0.05)$ commonly in all the three reservoirs (Table 02). Particularly, more than $80 \%$ of the daily smokers were found to consume alcohol in all the three reservoirs. Smoking is one of the major public health priorities worldwide and it was estimated that two million smokers die every year in China solely due to smoking related diseases (Qi et al., 2016). In Sri Lankan context, higher prevalence rates of smoking were observed among uneducated, middle-aged men who were from underprivileged families (Pereraet al., 2005). This study showed that percentages of smokers (at least rarely) in the fishing communities were $65 \%, 76 \%$, and $65 \%$, for Victoria, Sorabora and Ulhitiya, respectively which indicates that vast majority of the fishermen are smokers.

Table 02. Association between alcohol consumption and frequency of smoking of fishermen in three reservoirs

\begin{tabular}{cccccc}
\hline \multirow{2}{*}{ Reservoir } & Alcohol & \multicolumn{4}{c}{ Smoking (\%) } \\
\cline { 3 - 6 } consumption $^{1}$ & No smoking & Rarely & Occasionally & Daily \\
\hline Victoria & Yes & 63.0 & 100.0 & 96.6 & 82.6 \\
& No & 37.0 & 0.0 & 3.4 & 17.4 \\
Sorabora & Yes & 73.3 & 100.0 & 100.0 & 88.7 \\
& No & 26.7 & 0.0 & 0.0 & 11.3 \\
Ulhitiya & Yes & 43.6 & 66.7 & 66.7 & 82.2 \\
& No & 56.4 & 33.3 & 33.3 & 17.8 \\
\hline
\end{tabular}

${ }^{1}$ Yes $=$ teetotalers and $\mathrm{No}=$ all others.

Results of the linear logistic analysis between smoking (treated as a binary variable) and alcohol consumption and smoking are in Table 03. Outcome of the analysis varied depending on how smoking was categorized into binary groups. In Soraborareservoir, only one kind of categorization, i.e. nonsmokers versus smokers (rarely, occasionally or daily), led to a significant model with alcohol $(\mathrm{P}<0.05)$. In Victoria, two types of categorizations (nonsmokers versus smokers and less smoking (none or rarely) versus more smoking (occasionally or daily) produced significant results. In Ulhitiya, all three categorizations were significant (Table 03). 
Table 03 shows that for the first way of binary grouping (non-smoking or smoking at least rarely), odds ratio values were 4.18, 5.01 and 4.57 for Ulhitiya, Victoria and Sorabora respectively, which means that fishers who smoked at least rarely were about 4, 5 and 4.5 times more prone to consume alcohol than nonsmokers in those respective reservoirs. According to the second way of binary grouping, occasional and daily smokers were about 3.75 and 3.11 times more prone to use alcohol than rare or nonsmokers in Ulhitiya and Victoria reservoirs, respectively. The third kind of grouping shows that daily smokers in Ulhitiya tend to use alcohol about 4 times greater than their counterparts. Pereraet al. (2005) also confirmed that alcohol consumption seems to be positively associated with smoking in Sri Lanka. Both those habits lead to loss of their take home salary, more prominently (a greater percentage of salary is lost) in poor communities, leading to social disharmony and domestic conflicts.

Table 03. Estimates of Linear Logistic Model Analysis ${ }^{1}$ for tendency for alcohol consumption with respect to level of smoking among fishers in the three reservoirs

\begin{tabular}{|c|c|c|c|c|c|c|}
\hline \multirow[t]{2}{*}{ Tank } & \multirow[t]{2}{*}{ Level of smoking } & \multirow[t]{2}{*}{ Odds } & \multirow{2}{*}{$\begin{array}{l}\text { Odds } \\
\text { ratio }\end{array}$} & \multirow{2}{*}{$\begin{array}{l}\text { Log } \\
\text { odds } \\
\text { ratio }\end{array}$} & \multicolumn{2}{|c|}{$\begin{array}{l}\text { Confidence interval } \\
\text { for odds ratio }\end{array}$} \\
\hline & & & & & Minimum & Maximum \\
\hline \multirow[b]{2}{*}{ Ulhitiya } & Non smoking & 1.29 & \multirow[b]{2}{*}{4.18} & \multirow[b]{2}{*}{1.43} & \multirow[b]{2}{*}{1.81} & \multirow[b]{2}{*}{9.64} \\
\hline & $\begin{array}{l}\text { Smoking } \\
\text { (rarely/occasional/daily) }\end{array}$ & 0.31 & & & & \\
\hline \multirow[b]{2}{*}{ Ulhitiya } & Less smoking (non/rarely) & 1.03 & \multirow[b]{2}{*}{3.75} & \multirow[b]{2}{*}{1.32} & \multirow[b]{2}{*}{1.64} & \multirow[b]{2}{*}{8.56} \\
\hline & $\begin{array}{l}\text { More smoking (occasional/ } \\
\text { daily) }\end{array}$ & 0.27 & & & & \\
\hline \multirow[t]{2}{*}{ Ulhitiya } & $\begin{array}{l}\text { Non-daily } \\
\text { (none/rarely/occasional) }\end{array}$ & 0.88 & \multirow[t]{2}{*}{4.09} & \multirow[t]{2}{*}{1.41} & \multirow[t]{2}{*}{1.65} & \multirow[t]{2}{*}{10.11} \\
\hline & Daily & 0.21 & & & & \\
\hline \multirow[b]{2}{*}{ Victoria } & Non smoking & 0.58 & \multirow[b]{2}{*}{5.01} & \multirow[b]{2}{*}{1.61} & \multirow[b]{2}{*}{2.01} & \multirow[b]{2}{*}{12.50} \\
\hline & $\begin{array}{l}\text { Smoking } \\
\text { (rarely/occasional/daily) }\end{array}$ & 0.11 & & & & \\
\hline \multirow[b]{2}{*}{ Victoria } & Less smoking (non/rarely) & 0.42 & \multirow[b]{2}{*}{3.11} & \multirow[b]{2}{*}{1.13} & \multirow[b]{2}{*}{1.26} & \multirow[b]{2}{*}{7.65} \\
\hline & $\begin{array}{l}\text { More smoking } \\
\text { (occasional/daily) }\end{array}$ & 0.13 & & & & \\
\hline \multirow[b]{2}{*}{ Sorabora } & Non smoking & 0.36 & \multirow[b]{2}{*}{4.57} & \multirow[b]{2}{*}{1.51} & \multirow[b]{2}{*}{1.49} & \multirow[b]{2}{*}{13.96} \\
\hline & $\begin{array}{l}\text { Smoking } \\
\text { (rarely/occasional/daily) }\end{array}$ & 0.07 & & & & \\
\hline
\end{tabular}

${ }^{1}$ Significant models only $(\mathrm{P}<0.05)$.

\section{Income from fishing}

Analysis of variance procedure showed that the fishers in the three reservoirs were significantly different $(\mathrm{P}<0.05)$ with respect to mean daily income. Mean income in Ulhitiya (Rs. 1118.92) and Victoria (Rs. 943.89) were significantly higher than that of Sorabora (Rs 637.40). Across all 
reservoirs, mean daily income of teetotaler, rarely, occasionally and daily drinking groups were Rs. 1093.00, 1260.00, 1129.00, and 841.00 , respectively. The gap in income between the daily drinkers and rarely drinking group was significantly different $(\mathrm{P}<0.05)$ while the other gaps were nonsignificant. The interaction effect was not significant, which means income differences among the alcohol consumption groups were similar in the three reservoirs. The lowest income of daily drinkers could be linked with various associated habits such as lesser commitment and fishing effort indicated by fewer fishing days, lesser time spent per day and other non-committal habits.

\section{Living standard of the fishermen}

The survey revealed that the living standards of the fishers in the above three reservoirs were significantly different $(\mathrm{P}<0.05)$. However, majority of fishers' living standard was classified as fare indicating that income generated from either fishing or other sources, after covering their household expenses, was inadequate to improve their living conditions. Poor financial management also may be a reason for the poor living standard. It is widely believed that alcohol related behaviors have possible negative consequences with respect to the living standards of the consumers (Frantzeskouet al., 2014). However, in this study, living standard was significantly associated with level of alcohol consumption only in Sorabora reservoirwhere all fishermen reporting poor living standards were alcohol consumers (Table 04).

Table 04. Association between alcohol consumption of fishers and living standard in the three reservoirs

\begin{tabular}{ccrccc}
\hline \multirow{2}{*}{ Reservoir } & Alcohol & \multicolumn{4}{c}{ Living standard (\%) } \\
\cline { 3 - 6 } & consumption & Poor & Fare & Average & Satisfactory \\
\hline \multirow{2}{*}{ Victoria } & Yes & 79.0 & 79.8 & 80.8 & 100.0 \\
& No & 21.0 & 20.2 & 19.2 & 0.0 \\
Sorabora & Yes & 100.0 & 93.2 & 70.0 & N/A \\
& No & 0.0 & 6.8 & 30.0 & N/A \\
Ulhitiya & Yes & 55.0 & 70.8 & 54.6 & 75.0 \\
& No & 45.0 & 29.2 & 45.4 & 25.0 \\
\hline
\end{tabular}

${ }^{1} \mathrm{~N} / \mathrm{A}:$ not available

Odds ratio value of 6.35 in Table 11 for Sorabora shows that tendency for alcohol consumption of those who had favorable living standard (average or satisfactory) was around 6 times lesser than that of their counterparts. Lack of a significant association in the other two reservoirs require further investigation as to whether the fishermen who consume alcohol have any other income sources to balance their living status.

\section{Habit of saving excess income}

The survey revealed that saving of surplus income in the fishing community was very low in all three reservoirs. Due to seasonal pattern of the fish catch, low income periods and high income periods could be distinguished clearly coinciding with the 
rainy seasons (Wickremasinghe et al., 2009). As proper financial management was not maintained during the high catch period, most of the extra earning had been spent on non-essential items reducing the actual savings to a minimum or none. Chi-square test revealed that saving pattern significantly associated with alcohol consumption $(\mathrm{P}<0.05)$ in Sorabora and Ulhitiya reservoirs (Table 05) indicating that alcohol consumption has clearly led to low saving in those reservoirs.

Table 05. Association between alcohol consumption of fishers and saving habits in three reservoirs

\begin{tabular}{cccccc}
\hline \multirow{2}{*}{ Reservoir } & Alcohol & \multicolumn{4}{c}{ Percentage of savings from income earned } \\
\cline { 3 - 5 } consumption & 0 & $1-5$ & $6-10$ & $>10$ \\
\hline \multirow{2}{*}{ Victoria } & Yes & 78.9 & 83.3 & 71.4 & 0.0 \\
& No & 21.1 & 16.7 & 28.6 & 0.0 \\
Sorabora & Yes & 93.0 & 93.3 & 63.6 & 0.0 \\
& No & 7.0 & 6.7 & 36.4 & 0.0 \\
& Yes & 75.0 & 66.7 & 40.0 & 30.0 \\
& No & 25.0 & 33.3 & 60.0 & 70.0
\end{tabular}

Linear logistic model analysis showed that the tendency for alcohol consumption by the fishers who had poor saving habits was about 8 times and 5 times greater than that of their counterparts in Soraboraand Ulhitiyareservoirs, respectively (odds ratios 7.8 and 4.64 in Table 11). In Ulhitiya reservoir, when the habit of saving was classified as Zero saving $(0 \%)$ and Some saving $(>0 \%)$, it was found that the tendency for alcohol consumption by the fishers who had zero saving was about 2.4 times greater than that of the others (Table 11). When the habit of saving was reclassified as Less $(\leq 10 \%)$ and More $(>10 \%)$, the analysis showed that the tendency for alcohol consumption by the fishers who had less savings was about 5 times greater than those who had more savings in Ulhitiya reservoir.
The other socioeconomic factors studied such as education level of fisher, education level of children of the fisher, nature of engagement in fishing were not significantly associated with alcohol consumption $(\mathrm{P}>0.05)$.

\section{Participation in Fisheries Organization Activities}

The Fisheries Organizations of the reservoirs expect the regular participation of the fishermen in various activities carried out by the organization such as fry rearing cage construction and maintenance, regular feeding of fry, book and record keeping, and shramadana activities, etc. Results showed that the distribution of these two types of members among the three reservoirs were not significantly different $(\mathrm{P}>0.05)$. 
Table 06. Association between alcohol consumption of fishers and participation with fisheries organizational activities in three reservoirs

\begin{tabular}{lccc}
\hline \multirow{2}{*}{ Reservoir } & \multirow{2}{*}{ Alcohol consumption } & \multicolumn{2}{c}{ Participation in Fisheries Organization (\%) } \\
\cline { 3 - 4 } & & Active & Inactive \\
\hline Victoria & Yes & 76.5 & 93.3 \\
\multirow{3}{*}{ Sorabora } & No & 23.5 & 6.7 \\
& Yes & 86.7 & 92.6 \\
Ulhitiya & No & 13.3 & 7.4 \\
& Yes & 64.4 & 66.7 \\
& No & 35.6 & 33.3 \\
\hline
\end{tabular}

According to the results in Table 06, the significant association $(\mathrm{P}<0.05)$ expected between active response on Fisheries Organization and less consumption of alcohol was found only in Victoriareservoir. According to the linear logistic model, the tendency for use of alcohol by the inactive fishers was 4.3 times greater than that of active fishers in Victoria reservoir (Table 11). In the other two reservoirs, even the fishers who had active participation with the organizational activities were prone to use alcohol.

\section{Holding Positions in the Fisheries Societies}

When the three categories of fishers were examined with respect to their willingness to hold positions in the fisheries organization (previously held, presently holding and never held), chi-square analysis showed that the percentages of fishers fell into those categories were not significantly different among the three reservoirs $(\mathrm{P}<0.05)$. Taking up responsibilities in the fisheries organization indicates the willingness of fishers for active participation in reservoir management activities. Thus the results show that there seems always a certain portion of the fishing community who always would recognize the importance and come forward to bear responsibilities of the fisheries society for the betterment of the aquatic resource.

To investigate the association between tendency for alcohol consumption and willingness to take up offices of the fisheries society, alcohol consumption was classified into two categories as No (teetotalers) and Yes (all others). Table 07 shows that the majority of the fishers were in the Yes category regardless of their tendency to hold positions. Chi-square analysis on the data in table 07 proved that alcohol consumption pattern of fishers was significantly associated $(\mathrm{P}<0.05)$ with their willingness to take up positions in the organization was significant only in the Victoria reservoir, where the percentage of alcohol users was relatively higher in the non-volunteering group. In the other two reservoirs, alcohol use has not prevented them from taking up responsible positions in fisheries society. 
Table 07. Association between alcohol consumption of fishers and holding offices in the fisheries societies in three reservoirs

\begin{tabular}{ccccc}
\hline \multirow{2}{*}{ Reservoir } & \multirow{2}{*}{ Alcohol consumption } & \multicolumn{3}{c}{ Holding positions in the Fisheries Society } \\
\cline { 3 - 5 } & & Held & Holding & Never \\
\cline { 3 - 5 } & Yes & 57.9 & 76.0 & 86.4 \\
Victoria & No & 42.1 & 24.0 & 13.6 \\
Sorabora & Yes & 92.3 & 75.0 & 90.2 \\
& No & 7.7 & 25.0 & 9.8 \\
Ulhitiya & Yes & 52.6 & 57.1 & 69.2 \\
& No & 47.4 & 42.9 & 30.8 \\
\hline
\end{tabular}

The results of the logistic model analyses of the current and subsequent sections are summarized in Table 11. For example, the odds ratio of 2.95 in the table relevant to holding positions in Victoria reservoir implies that the fishers who never held any responsible positions in the fisheries organization were about 3 times more prone to consume alcohol than the volunteering group of fishers. It was clear from the survey that mostly a small set of members have the commitment to carry out the responsibilities of their Fisheries Organization but majority were reluctant to carry the burden voluntarily for the benefit of the community and their aquatic resource.

\section{Training and Awareness Programs}

When the level of participation of fishermen in the training programs conducted by the Government authorities is measured by their attendance, Chi square analysis revealed that the level of participation of fishers in such awareness programs was significantly different among reservoirs $(\mathrm{P}<0.05)$. However, Chi square analysis conducted within each reservoir has shown that the association between attending training and awareness programs and use of alcohol was significant $(\mathrm{P}<0.05)$ only in Victoria reservoir where a greater level of nonparticipants were alcohol users (Table 08). These results indicate that management measures to be taken with respect to improving participation in awareness programs must be reservoir specific.

It is widely accepted that extension advice, trainings and technology promotion has an impact on poverty reduction efforts in remote areas (Adugna, 2013). Conducting well planned training and awareness programs on laws and regulations, and good practices with regard to fisheries are effective for aquatic resource management and uplifting socio economic standards of the fishing community. According to the linear logistic model estimates in Victoria reservoir (odds ratio of 2.66 in Table 11), tendency for alcohol consumption of the fishers who participated in training and awareness programs was about 2.7 times lower than those who did not participate in those programs. Deepthi et al. (2014) emphasized the importance of Governments organizing training programs for the fishermen on various socio economic and fishery management aspects and providing good education to the fishing community to uplift their living standards. 
Table 08. Association between alcohol consumption of fishers and participation at the training and awareness programs in the three reservoirs

\begin{tabular}{cccc}
\hline \multirow{2}{*}{ Reservoir } & $\begin{array}{c}\text { Alcohol } \\
\text { consumption }\end{array}$ & \multicolumn{2}{c}{ Training and awareness programs (\%) } \\
\cline { 3 - 4 } & Yes & 72.1 & Participated \\
\hline Victoria & No & 27.9 & 87.3 \\
& Yes & 83.8 & 12.7 \\
Sorabora & No & 16.2 & 94.1 \\
& Yes & 50.0 & 5.9 \\
Ulhitiya & No & 50.0 & 68.5 \\
& & & 31.5 \\
\hline
\end{tabular}

Janko et al. (2015) pointed out that carefully planned awareness programs could fill the perception gap among fishermen related to reservoir fishery management aspects.However, as this study has shown that the impact of awareness programs on good social behavior had no impact on mitigating alcohol usage among fishers in the other two reservoirs, a thorough retrospective investigation must be carried out to identify the shortcomings and failures of those programs.

\section{Licensing and Registration}

According to the Government regulations, every fisherman is required to obtain operational license for fishing as well as registration certificate for the boats and those should be renewed annually. Due to some issues pertaining to the Government, issuing certificates and registration was not implemented in Soraborareservoir during the survey period (2014-15). Chi square analysis showed that the differences among reservoirs in number of fishers obtaining license were significant $(\mathrm{P}<0.05)$. However, obtaining an operational license for fishing was not significantly associated with alcohol consumption pattern in any of the reservoirs $(\mathrm{P}>0.05)$. However, there was a significant association $(\mathrm{P}<0.05)$ between boat registration and alcohol consumption in Victoria and Ulhitiya reservoirs where percentage of alcohol users was higher in the group of those who have not obtained or renewed their registration (Table 09). Linear logistic model analysis (odds ratios of 4.21 and 8.31 in Table 11) revealed that fishermen who had not registered their boats had the tendency to consume alcohol about 4 and 8 times more than those who registered in Victoria and Ulhitiya reservoirs, respectively (Table 11). Thus in those two reservoirs, lack of adherence to fishing community rules and socially accepted behaviors seem to be confounded in certain groups of fishers. 
Table 09. Association between alcohol consumption of fishers and boat registration in the three reservoirs

\begin{tabular}{cccc}
\hline \multirow{2}{*}{ Reservoir } & Alcohol & \multicolumn{2}{c}{ Boat registration (\%) } \\
\cline { 3 - 4 } & consumption & Registered & Not registered \\
\hline \multirow{2}{*}{ Victoria } & Yes & 73.2 & 92.0 \\
& No & 26.8 & 8.0 \\
\multirow{2}{*}{ Sorabora ${ }^{1}$} & Yes & N/A & N/A \\
& No & N/A & N/A \\
\multirow{2}{*}{ Ulhitiya } & Yes & 56.9 & 91.7 \\
& No & 43.1 & 8.3 \\
\hline
\end{tabular}

${ }^{1}$ No registration was implemented inSorabora during the study period.

\section{Participation of Fishermen in Raids}

This study showed that the percentage of fisher participation in raids conducted by the Government to catch illegal fishing activities did not vary among the three reservoirs, according to the Chi square analysis $(\mathrm{P}>0.05)$. Table 10 shows that the percentage of alcohol consumers among those who have never volunteered for raids (non-participant group) is greater than the respective percentage among volunteers (participants) in all three reservoirs. However, a significant $(\mathrm{P}<0.05)$ association expected between participation in raids and lesser consumption of alcohol was found only in Ulhitiya reservoir. In Ulhitiya reservoir, majority of those who participated in the raids were teetotalers (Table 10).
However, in the other two reservoirs, attitudes towards alcohol consumption or abstinence from alcohol consumption seem less related to their choice of voluntary participation in safeguarding their aquatic resources.

It has been observed that various forms of unlawful fishing practices take place in perennial reservoirs in Sri Lanka (Wickremasinghe et al., 2009; Wickremasinghe et al., 2018) such as use of illegal fishing methods and unpermitted fishing gear. Over the years, NAQDA has been launching frequent raids and the captured individuals and gear are produced to the courts for legal actions.

Table 10. Association between alcohol consumption of fishers and participation in raids in three reservoirs

\begin{tabular}{cccc}
\hline \multirow{2}{*}{ Reservoir } & \multirow{2}{*}{ Alcohol consumption } & \multicolumn{2}{c}{ Participation in Raids (\%) } \\
\cline { 3 - 4 } & Yes & Participated & Not Participated \\
\hline Victoria & No & 25.4 & 82.8 \\
& Yes & 80.0 & 17.2 \\
Sorabora & No & 20.0 & 90.0 \\
& Yes & 38.1 & 10.0 \\
Ulhitiya & No & 61.9 & 71.1 \\
& & & 28.9 \\
\hline
\end{tabular}


As the manpower from the Government alone is not sufficient to carry out such risky tasks, often assistance is sought from the fishers who are living around the reservoirs. Fishermen who were really concerned about sustainability of the fishery participated in the raids voluntarily. Such voluntary involvement of fishers is vital for prevention of the harmful, illegal fishing activities (Wickremasingheet al., 2018).

Table 11. Estimates of Linear Logistic Model Analysis ${ }^{1}$ for Tendency for Alcohol Consumption in three Reservoirs

\begin{tabular}{|c|c|c|c|c|c|c|c|}
\hline \multirow[t]{2}{*}{ Tank } & \multirow[t]{2}{*}{ Factor } & \multirow[t]{2}{*}{ Levels } & \multirow[t]{2}{*}{ Odds } & \multirow[t]{2}{*}{$\begin{array}{l}\text { Odds } \\
\text { ratio }\end{array}$} & \multirow{2}{*}{$\begin{array}{l}\text { Log } \\
\text { Odds } \\
\text { ratio }\end{array}$} & \multicolumn{2}{|c|}{$\begin{array}{l}\text { Confidence interval } \\
\text { for odds ratio }\end{array}$} \\
\hline & & & & & & Minimum & Maximum \\
\hline \multirow{8}{*}{ Victoria } & \multirow{2}{*}{$\begin{array}{l}\text { Organization } \\
\text { positions }\end{array}$} & $\begin{array}{l}\text { Held } \\
\text { (held/holding) }\end{array}$ & 0.46 & \multirow[t]{2}{*}{2.95} & \multirow[t]{2}{*}{1.08} & \multirow[t]{2}{*}{1.22} & \multirow[t]{2}{*}{7.11} \\
\hline & & Never held & 0.15 & & & & \\
\hline & \multirow{2}{*}{$\begin{array}{l}\text { Awareness } \\
\text { programs }\end{array}$} & Participated & 0.38 & \multirow{2}{*}{2.66} & \multirow{2}{*}{0.97} & \multirow{2}{*}{1.08} & \multirow{2}{*}{6.51} \\
\hline & & Never & 0.14 & & & & \\
\hline & \multirow{2}{*}{$\begin{array}{l}\text { Boat } \\
\text { registration }\end{array}$} & Registered & 0.36 & \multirow{2}{*}{4.21} & \multirow{2}{*}{1.43} & \multirow{2}{*}{1.35} & \multirow{2}{*}{13.08} \\
\hline & & Not registered & 0.08 & & & & \\
\hline & \multirow{2}{*}{$\begin{array}{l}\text { Organization } \\
\text { response }\end{array}$} & Active & 0.30 & \multirow{2}{*}{4.3} & \multirow{2}{*}{1.46} & \multirow{2}{*}{0.95} & \multirow{2}{*}{19.41} \\
\hline & & Inactive & 0.07 & & & & \\
\hline \multirow{4}{*}{ Sorabora } & \multirow{2}{*}{$\begin{array}{l}\text { Living } \\
\text { standard }\end{array}$} & Unfavorable & 0.42 & \multirow{2}{*}{6.35} & \multirow{2}{*}{1.84} & \multirow{2}{*}{2.03} & 1081 \\
\hline & & Favorable & 0.06 & & & & 10.01 \\
\hline & Souingr & Poor & 0.57 & $82+>$ & 205 & 15 & 2407 \\
\hline & Navings & Better & 0.07 & $1.0 J$ & 2.00 & $2.7 \mathrm{~J}$ & ו \\
\hline & Boat & Registered & 0.75 & 831 & 11 & 101 & 6780 \\
\hline & registration & Not registered & 0.09 & & & & \\
\hline & Participation & Never & 1.62 & 300 & 138 & 148 & 1 月 78 \\
\hline & in raids & Participated & 0.40 & (5) & 1.00 & 1.40 & 10.10 \\
\hline Juhitive & Soving & Poor & 1.85 & 64 & 153 & 166 & 1201 \\
\hline Sinti & Navingo & Better & 0.39 & 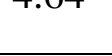 & 1.00 & 1.00 & דיל. 12. \\
\hline & Savings & Zero & 0.78 & 236 & 086 & 105 & 531 \\
\hline & Navings & Good & 0.33 & 2.00 & 0.00 & 1.00 & - \\
\hline & Savings & Less & 2.33 & 503 & 61 & 22 & 77 \\
\hline & Navings & More & 0.46 & J.0J & 1.01 & 1.22 & 20.12 \\
\hline
\end{tabular}

${ }^{1}$ Significant models only $(\mathrm{P}<0.05)$. 
Results of linear logistic model analysis (odds ratio of 3.99 in Table 11) shows that in Ulhitiya, the tendency for use of alcohol by fishers, who participated in raids was about 4 times lesser than that of fishers who did not participate in raids. However, overall results show that alcohol consumption related social behaviors are complex and could be related to diverse perceptions on social harmony. For example, by investigating the fishers during the survey and by interviewing NAQDA officials it was detected that in some cases over consumption of alcohol had enhanced antisocial behavior and lack of sense of social responsibility while in some other cases occasional consumption of alcohol as a group had provided a platform for social interaction and binding, even to a degree of taking risks on behalf of betterment of the entire community. In the situations where both such groups are classified together as alcohol consumers, statistical association between alcohol consumption and participation in raids could turn out to be non-significant.

\section{Remedial Measures}

The results of this study revealed that the tendency to consume alcohol has a significant impact on some socioeconomic aspects and social attitudes of the fishing communities in Victoria, Sorabora and Ulhitiya reservoirs. Frantzeskouet al. (2014) emphasized that alcohol addiction among fishermen need to be thoroughly investigated as they represent occupational risks to their future career in fisheries sector. However, in contrary to the popular belief, this study found that alcohol consumption had very little impact on many other livelihood and fisheries management related variables investigated such as fisher's education level, children's education level, the level of engagement in fishing, obtaining license for fishing, engaging in illegal fishing practices and attitudes of the fishers with respect to organizing into fisheries societies and to comply to fishing regulations in the three reservoirs. Even, for the factors which were significantly associated with alcohol consumption in this study, there were fishers deviated from the widely accepted beliefs about alcohol consumption. One of the reasons for the above results could be that there exists a great variation among the alcohol consumers with respect to the level of consumption. According to the NAQDA officials monitoring the fishing community, only some fishers could be treated as addicted demonstrating irresponsible behavior while many others could be considered as moderate drinkers or social drinkers who even might be prone to teamwork and social harmony. These complex social interactions and attitudes must be thoroughly investigated in order to identify the real threats to aquatic resource management. It is also important to review the present fisheries management policies and to investigate on how to achieve active involvement of the fishermen in the management process as this attitude will lead to improve the fisheries management in general and the socioeconomic conditions of fishermen (Alhabsi, 2012).

\section{Conclusions}

According to the results of this study, considerable prevalence of alcohol use was evident among the fishermen in the three reservoirs. The situation seems more critical since alcohol use is accompanied by smoking which adversely affects the home economy. However, contrary to the popular belief, many alcohol users of the three reservoirs have come forward as active members to contribute to fisheries management. It is also clear that alcohol use has little or no impact on many of the socioeconomic parameters investigated and the situation is reservoir dependent. Thus in 
terms of aquatic resource management, the reservoir specific management strategies must be implemented depending on the level of alcohol consumption among fishermen and the related issues, instead of implementing blanket rules across reservoirs.

\section{Acknowledgement}

The financial support provided by the National Research Council (Grant No 13156) is gratefully acknowledged.

\section{References}

Adugna, E. and Sileshi, M. (2013). Determinants of poverty in (agro-) pastoral societies of Southern Ethiopia. Livestock Research for Rural Development25(2).

Alhabsi, M. S. (2012). The fisheries community of Albatinah in Oman: ASocioeconomic overview. Journal of Fisheries Sciences. 6(3): 215-223.

Anonymous, (2009). Annual Report 2008. National Aquaculture Development Authority of Sri Lanka. Pelawatta, Battaramulla, Sri Lanka.

Anonymous, (2013). Fisheries sector development strategy 2010-2013. Ministry of Fisheries and Aquatic Resources Development. Maligawatta, Colombo 10.

Anonymous, (2016a). Fisheries Performance. Ministry of Fisheries and Aquatic Resources Development. Maligawatta, Colombo 10.

Anonymous, (2016b). Annual Report 2015. National Aquaculture Development Authority of Sri Lanka. Pelawatta, Battaramulla, Sri Lanka.
Anonymous, (2018). Jalageevi Udanaya2018. National Aquaculture Development Authority of Sri Lanka. Pelawatta, Battaramulla, Sri Lanka.

Chinnakali, P., Thekkur, P., Kumar, M., Ramaswamy, G., Bharadwaj, B. and Roy, G. (2016). Alarmingly high level of alcohol uses among fishermen: A community based survey from a coastal area of south India. Journal of Forensic Leg Med. 42(41):4.

Deepthi, A., Babu, Y.M., Dana, S. S. and Sujathkumar, N. V. (2014). Constraints encountered by fishermen due to fishing ban and their awareness status towards fishing ban and sustainability. European Journal of Experimental Biology. 4 (4):131-135.

Fernando, W.M.j.R., Chandrasoma, J., Pushpalatha, K.B.C. and Kulathilaka, M. (2015). Co-management of the fishery of Senanayake Samudra, a large perennial reservoir in Sri Lanka. Sri Lanka Journal of Aquatic Science. 20 (2): 9-18.

Frantzeskou, E., Jensen, O. and Linos, A. (2014). Prevalence of Health Risk Factors among Fishermen - A Review. Occupational Medicine \& Health Affairs. 2(2): 2-157.

George, A., Varghese, C., Sankaranaravanan, R. and Nair, M.K. (1994). Use oftobacco and alcoholic beverages by children and teenagers in a low-income coastal community in South India. Journal of Cancer Education. 9(2):111-3.

Greene, W. H. (2000). EconometricAnalysis. $4^{\text {th }}$ Ed. McGraw Hill Publ. NY.Janko, A.M. and Zemedu, L. (2015). Fisherman's willingness to pay for fisheries 
management: The case of lake Zeway, Ethiopia. Journal of Fisheries Sciences. 9(4): 016-022.

Lawrie, T., Matheson, C., Rithchie, L., Murphy, E. and Bond, C. (2004). The health and lifestyle of Scottish fishermen: a need for health promotion. Health Education Research. 19(4): 373-379.

Perera, B., Fonseka, P., Ekanayaka, R. and Lelwala, E. (2005). Smoking in adults in Sri Lanka: prevalence and attitudes. Asia Pacific Journal of Public Health. 17(1):405.

Qi, F., Liu, J.S., Lin, S.X., Zhu, H.P., Gao, Q.M., Liu, D.D., Dong, P., Jia, Y. and Wang, Z. (2016). Smoking cessation: A case study of a pilot integrated program in Qingdao, China. Journal of Health and Medical Economics. 2(2).

Rane, P.P., Narayanan, P., Binu, V. and Unnikrishnan, B. (2016). Prevalence of Tobacco and Alcohol Consumption among Fishermen in Udupi Taluk' Karnataka, India: A Cross-Sectional Study.Asian Pacific Journal of Cancer Prevention 17(4):1733-7.
SAS Institute Inc. (2008). SAS/STAT® 9.2 User's Guide, Cary, NC, USA.

Tumwesigye, N.M., Atuyambe, L., Wanyenze, R.K., Kibira, S.P.S., Li, Q., Mangen, F.W. and Wagner, G. (2012). Alcohol consumption and risky sexual behavior in the fishing communities: evidence from two fish landing sites on Lake Victoria in Uganda.BMC Public Health. 12(1):1.

Wetzel, R.G. (1983). Limnology (Second Edition). Philadelphia: Saunders College Publishing, Toronto, Ontario. 767.

Wickremasinghe, E.S., Dematawewa, C.M.B. and Edirisinghe, U. (2009). Illegal fishing practices: a case study in Sorabora reservoir, Sri Lanka. Sri Lanka Journal of Animal Production. 5(1):3-27.

Wickremasinghe, E.S., Dematawewa, C.M.B. and Edirisinghe, U. (2018). Investigation of critical issues associated with illegal fishing practices in three perennial reservoirs in Sri Lanka. Tropical Agriculture Research. 30: (accepted). 